\title{
Ocorrência de leite com instabilidade da caseína em Santa Vitória do Palmar, RS
}

\section{Occurrence of milk with casein instability in Santa Vitória do Palmar, RS}

\author{
Daniela dos Santos de Oliveira, ${ }^{*}$ Carina Martins de Moraes, ${ }^{*}$ Talita Bandeira Roos, ${ }^{*}$ Rogério Fôlha Bermudes, ${ }^{*}$ \\ Cláudio Dias Timm $* * *$
}

\begin{abstract}
Resumo
O objetivo do presente trabalho foi determinar a ocorrência de leite com instabilidade da caseína no extremo sul do Brasil. Duzentas e oitenta e duas amostras de leite cru foram coletadas em estabelecimentos produtores de leite do município de Santa Vitória do Palmar, Rio Grande do Sul (RS). As amostras foram analisadas pelo teste do álcool etílico a 70\% (v/v), acidez titulável e contagem de células somáticas (CCS). Leites com resultado positivo no teste do álcool, CCS menor que $1,8 \times 10^{6}$ células $/ \mathrm{mL}$ e acidez até $18^{\circ} \mathrm{D}$, foram considerados com instabilidade da caseína. Das amostras sem acidez adquirida e com CCS insuficiente para alterar a estabilidade da caseína, 33,93\% apresentaram resultado positivo no teste do álcool. A maior e a menor ocorrência de leite com instabilidade da caseína foram observadas no outono $(49,25 \%)$ e no verão $(19,05 \%)$, respectivamente. Os resultados obtidos ressaltam a importância da pesquisa de leite com instabilidade da caseína, quantificando-a e disponibilizando dados para cálculo de impacto econômico do problema na região estudada.
\end{abstract}

Palavras-chave: instabilidade da caseína, teste do álcool, leite, acidez, mastite.

\begin{abstract}
The aim of the present work was to determine the occurrence of milk with casein instability in the extreme south of Brazil. Two hundred and eighty two samples of raw milk were collected from dairy farms in district of Santa Vitória do Palmar, Rio Grande do Sul (RS). The samples were analyzed by alcohol $70 \%(\mathrm{v} / \mathrm{v})$ test, titrable acidity, and somatic cell count (SCC). Milk with positive result for alcohol test, SCC lesser than $1.8 \times 10^{6} \mathrm{cells} / \mathrm{mL}$ and acidy until $18^{\circ} \mathrm{D}$ were considered as milk with casein instability. Among the samples without acquired acidity and without SCC enough for changing the casein stability, 33.93\% showed positive results for the alcohol test. The highest and the lowest occurrence of milk with casein instability were found in autumn (49.25\%) and in summer (19.05\%), respectively. The results highlight the importance of the search of milk with casein instability, quantifying it and making data available for evaluation of the economic impact of the problem in the studied region.
\end{abstract}

Keywords: casein instability, alcohol test, milk, acidity, mastitis.

\section{Introdução}

$\mathrm{Na}$ avaliação higiênico-sanitária do leite cru são utilizados padrões e técnicas especiais, como a verificação da acidez e a contagem de células somáticas (CCS) (Langoni, 2000). Muitas indústrias de laticínios utilizam a prova do álcool para verificar se o leite apresenta problemas de estabilidade térmica.

De acordo com a metodologia recomendada pelos Métodos Analíticos Oficiais Físico-químicos para Controle de Leite e Produtos Lácteos (Brasil, 2003), a prova do álcool pode ser usada como um método rápido para estimar a estabilidade das proteínas do leite durante o processamento térmico, uma vez que o leite com elevada acidez ou desequilíbrio salino coagula quando misturado ao álcool etílico. A elevação da acidez é provocada pela hidrólise da lactose por enzimas microbianas, com formação de ácido láctico (Pereira et al., 2001).

As células somáticas do leite são compostas basicamente por células de descamação do epitélio secretor e leucócitos de origem sangüínea. À medida que a CCS no leite aumenta, ocorre elevação no teor de enzimas, como plasmina e outras proteases oriundas do sangue ou produzidas pelas células de defesa da vaca, que hidrolisam porções da caseína, podendo deixá-la instável ao aquecimento (Philpot, 1998; Moussaqui et al., 2002).

Os primeiros registros de caseína instável em leite não-ácido ocorreram em Utrecht, na Holanda, em 1930 (Mitamura, 1937). De acordo com Davies e White (1958), nos casos de Utrecht, a instabilidade da proteína ao calor e ao etanol estava relacionada com a concentração de íons de cálcio no leite. Pecorari et al. (1984), estudando leite com resultado positivo na prova do álcool, encontraram valores baixos para os teores de caseína, lactose e minerais (cálcio e fósforo) e alterações nas propriedades físico-químicas, como baixa acidez titulável e elevado pH. Em estudo realizado em Cuba com 227 propriedades leiteiras com 15.000 vacas, no qual foram excluídos leites positivos no California Mastitis Test (CMT) com duas ou

\footnotetext{
*Inspeção de Leite e Derivados, Faculdade de Veterinária, Universidade Federal de Pelotas.

**Autor para correspondência. Inspeção de Leite e Derivados, Faculdade de Veterinária, Universidade Federal de Pelotas, campus universitário, prédio 34, Pelotas, RS, CEP 96010-900. E-mail: timm@ufpel.tche.br
} 
mais cruzes, $79 \%$ das amostras analisadas apresentaram resultado positivo no teste do álcool e acidez menor que $13^{\circ} \mathrm{D}$ (Ponce e Hernández, 2001). No Rio de Janeiro, Brasil, Donatele et al. (2003), analisando a relação do teste de alizarol a $72 \%$, acidez e contagem de células somáticas em 847 amostras de leite de uma propriedade, observaram que 287 amostras estavam instáveis ao alizarol, 257 apresentaram $\mathrm{pH}$ entre 6,4 a 6,8 e 30 acima de 6,$8 ; 171$ demonstraram acidez titulável de 15 a 18으, 77 menos que $15^{\circ} \mathrm{D}$ e 39 de 18,1 a $20^{\circ} \mathrm{D}$.

As indústrias realizam rotineiramente a prova do álcool nos estabelecimentos leiteiros, coletando para o tanque isotérmico do caminhão transportador somente o leite que apresente reação negativa nesta prova. Nas propriedades em que o leite apresenta reação positiva na prova do álcool, os produtores arcam com sérias perdas econômicas, devido ao não-recebimento pelo leite produzido. Entretanto, existem poucos estudos quanto à ocorrência de leite com instabilidade da caseína não decorrente de acidez adquirida ou mastite, não tendo sido ainda definida a importância do problema, devido à falta de dados para a quantificação das perdas na produção e seu impacto econômico. O presente trabalho teve como objetivo determinar a ocorrência de leite com estabilidade da caseína no município de Santa Vitória do Palmar, RS.

\section{Material e métodos}

Durante o período de abril de 2002 a março de 2003, 282 amostras de leite cru de vacas das raças Holandês, Jersey e mestiços foram obtidas diretamente de tanques de resfriamento de estabelecimentos rurais produtores de leite no município de Santa Vitória do Palmar, Rio Grande do Sul. As amostras foram obtidas no momento da coleta a granel do leite para envio à indústria de beneficiamento, constituindose, portanto, de mistura de leite de quatro ordenhas, ou seja, de leite com até 48 horas da ordenha. Foram realizadas 2 coletas por estação do ano. As amostras foram acondicionadas em caixas isotérmicas contendo gelo e enviadas ao Laboratório de Inspeção de Produtos de Origem Animal (LIPOA) da Universidade Federal de Pelotas para realização das análises.
As amostras foram analisadas na prova do álcool etílico a $70 \%$ (v/v) e pela titulação da acidez com o método de Dornic, conforme os Métodos Analíticos Oficiais Físico-Químicos para Controle de Leite e Produtos Lácteos (Brasil, 2003).

A prova do álcool consistiu na mescla de $2 \mathrm{~mL}$ de álcool etílico a $70 \%(v / v)$ com $2 \mathrm{~mL}$ de leite cru integral. As reações que apresentaram formação de grumos foram consideradas positivas.

A determinação da acidez pelo método de Dornic foi realizada pela titulação de $10 \mathrm{~mL}$ de leite com substância alcalina de normalidade conhecida (hidróxido de sódio N/9), utilizando fenolftaleína como indicador de $\mathrm{pH}$. O resultado foi medido em graus Dornic ( $\left.{ }^{\circ} \mathrm{D}\right)$, sendo $1^{\circ} \mathrm{D}$ correspondente a $0,1 \mathrm{~mL}$ da solução alcalina gasta na titulação.

As amostras de leite para CCS foram acondicionadas em frascos contendo conservante bronopol (2-bromo-2nitropropano-1,3-diol) e enviadas ao Laboratório de Controle de Qualidade de Alimentos da Universidade de Passo Fundo em caixas isotérmicas contendo gelo. As amostras foram analisadas através de citometria de fluxo em contador eletrônico Somacount, de acordo com recomendações da International Dairy Federation (IDF-FIL, 1995).

Para descartar leites instáveis devido à acidez adquirida ou à mastite, foram consideradas como amostras de leite com instabilidade da caseína apenas aquelas com resultado positivo na prova do álcool que apresentaram acidez até 18으 e CCS abaixo de $1,8 \times 10^{6}$ células $/ \mathrm{mL}$.

\section{Resultados e discussão}

\section{Freqüência do leite com instabilidade da caseína}

Das 282 amostras de leite analisadas, 186 (65,95\%) apresentaram acidez titulável até 18D (leite não-ácido) e 96 (34,05 \%) acima de 18D (leite ácido). Dentre as amostras nãoácidas, 18 (6,38 \% do total de amostras) apresentaram CCS igual ou maior que $1,8 \times 10^{6}$ células $/ \mathrm{mL}$ e $168(59,57 \%)$ CCS inferior a 1,8 x $10^{6}$ células $/ \mathrm{mL}$. Das amostras não-ácidas com CCS menor que 1,8 x 106 células $/ \mathrm{mL}, 111$ (39,36\% do total de amostras) apresentaram reação negativa na prova do álcool e $57(20,21 \%)$ reação positiva (Figura 1).

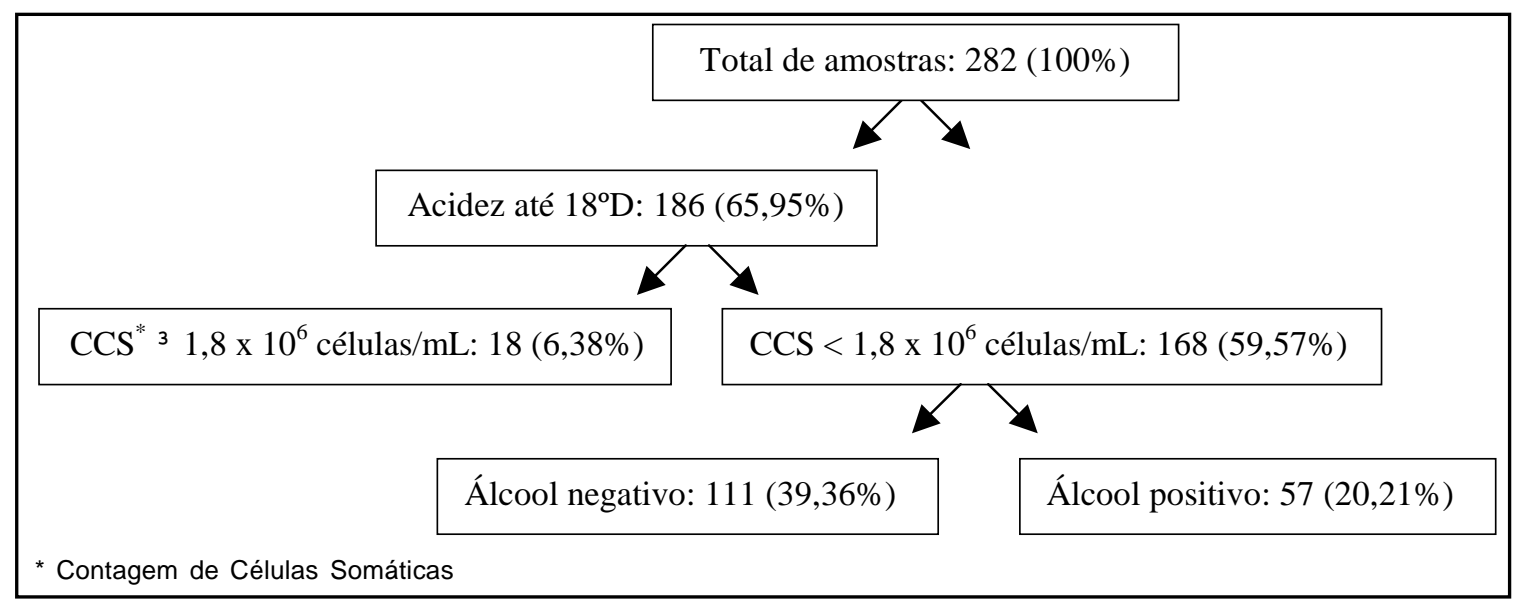

Figura 1: Resultados das análises de acidez, contagem de células somáticas e prova do álcool em amostras de leite coletadas no município de Santa Vitória do Palmar, RS, no período de abril de 2002 a março de 2003. 
De acordo com os resultados encontrados, $33,93 \%$ (57 amostras) das amostras sem acidez adquirida e com CCS insuficiente para alterar a estabilidade da caseína (20,21\% do total de amostras analisadas) foram positivas no teste do álcool a $70 \%(\mathrm{v} / \mathrm{v})$. Os estabelecimentos rurais que produziram esses leites não tiveram sua produção coletada pela indústria láctea, que não aceita leite com reação positiva no teste do álcool. No presente estudo, foi utilizado álcool etílico na concentração de $70 \%$ (v/v) para a realização dos testes, porque, na ocasião da coleta das amostras, era essa a concentração utilizada pelos compradores para avaliar o leite de seus fornecedores na região. Entretanto, com a entrada em vigor da Instrução Normativa no 51 do Ministério da Agricultura, Pecuária e Abastecimento (Brasil, 2002), o percentual de leite rejeitado pela indústria tenderá a aumentar, uma vez que o teste do álcool ou alizarol passará a ser realizado na concentração de $72 \%(\mathrm{v} / \mathrm{v})$.

Os resultados encontrados são similares aos de outros trabalhos realizados na região sul do Brasil e no Uruguai. Timm et al. (2002), estudando leite com instabilidade protéica, encontraram em 274 amostras, $126(45,99 \%)$ com reação positiva na prova do álcool 70\% e $148(54,01 \%)$ apresentaram reação negativa. Das amostras positivas, 22 (17,46\%) estavam com acidez acima de $20^{\circ} \mathrm{D}$, sendo consideradas com caseína instável devido à acidificação pela multiplicação bacteriana. Cento e quatro $(82,54 \%)$ amostras positivas na prova do álcool apresentaram acidez até $20^{\circ} \mathrm{D}$, indicando que a perda da estabilidade protéica foi causada por outros fatores que não a acidez. Barros et al. (2000), estudando variações da composição do leite individual em função da positividade à prova do álcool, no Uruguai, encontraram 146 amostras de leite negativas na prova do álcool e 70 positivas.

\section{Freqüência de leite com instabilidade da caseína durante as estações do ano}

A maior e a menor ocorrência de leite com instabilidade da caseína foram observadas no outono $(49,25 \%)$ e no verão $(19,05 \%)$, respectivamente (Tabela 1$)$. Os resultados estão de acordo com Barros et al. (1999), que encontrou variações na estabilidade da caseína em função da estação, estando a alteração, mais freqüente no outono e na mudança de inverno para a primavera, aparentemente relacionada com épocas de seca. Essas variações foram associadas a dietas ou pastos ricos em cálcio, com deficiências ou desbalanços minerais ( $\mathrm{Ca}, \mathrm{P}, \mathrm{Mg}$ ), e a mudanças bruscas da dieta, sendo inconstante a resposta a suplementações minerais (Barros, 2001). Evidências de que dietas podem influenciar na estabilidade do leite ao etanol foram relatadas por Davies e White (1958), que observaram que vacas alimentadas com plantas ricas em cálcio, apresentaram leite instável para o etanol e acidez normal.
No outono, em Santa Vitória do Palmar, ocorre uma menor oferta de alimentos para os animais. A alimentação oferecida é à base de resteva de arroz e pastagem nativa, pois o corte da lavoura de arroz é realizado até fim do mês de março, ficando os campos com o resto da palha de arroz, que é aproveitada pelos produtores para alimentar os animais. $\mathrm{O}$ desequilíbrio da relação cálcio-fósforo a favor do cálcio na alimentação dos animais durante o outono pode ter contribuído para um aumento do teor de cálcio no leite, ocasionando uma maior freqüência de leite com instabilidade da caseína nesta época. Segundo Lucci (1997), a palha de arroz é muito rica em cálcio, tendo alto teor de sílica e de lignina, uma substância polifenólica, resistente a degradação fermentativa e não tem valor nutritivo para o ruminante, apresentando digestibilidade baixa.

Principalmente durante o outono e inverno, as pastagens na região apresentam deficiência de fósforo e um relativo excesso de cálcio (González e Scheffer, 2002). Segundo Varnam e Sutherland (1995), a distribuição do cálcio, citrato, magnésio e fosfato entre as fases solúveis e coloidais e suas interações com as proteínas do leite têm importante conseqüência para a estabilidade do leite e de produtos lácteos. De acordo com Barros et al. (1998), o teor de cálcio ionizado está diretamente relacionado com a positividade da prova do álcool, existindo uma relação inversamente proporcional entre estabilidade das proteínas e o teor natural de cálcio iônico do leite.

As vacas alimentadas com concentrados disponibilizam níveis altos de ácidos graxos previamente formados para a produção do leite, diminuindo a síntese "de novo" de ácidos graxos na glândula mamária. O contrário acontece com animais alimentados com volumosos. Os níveis de citrato, o qual retém cálcio e estabiliza a caseína (Horne e Parker, 1981; Walstra e Jenness, 1987), encontram-se baixos durante a síntese "de novo" (Varnam e Sutherland, 1995). Na região onde se realizou o estudo, a alimentação no outono é baseada em volumosos, portanto, com produção de leite com menos citrato e mais cálcio dissolvido. Desta forma, a caseína do leite se apresentaria mais instável. Ponce (1999) relatou a ocorrência de leite positivo na prova do álcool em Cuba, associada à alimentação de animais da raça Holandês de alto potencial genético baseada em cana-de-açúcar como forragem durante a época de seca.

Os resultados obtidos no presente trabalho ressaltam a importância da pesquisa de leite com instabilidade da caseína, quantificando-a e disponibilizando dados para cálculo de impacto econômico do problema na região estudada. 


\section{Referências}

BARROS, L. Transtornos metabólicos que afetam a qualidade do leite. In: GONZÁLEZ, F.H.D.; DÜRR, J.W., FONTANELI, R.S. (Ed.). Uso do leite para monitorar a nutrição e o metabolismo de vacas leiteiras. Porto Alegre: UFGRS, 2001. p. 44-57.

BARROS, L.; DENIS. N.; GONZALEZ, A.; NUÑEZ, A. lonized calcium related to alcohol test in milk. INTERNATIONAL CONFERENCE ON PRODUCTION DISEASES IN FARM ANIMALS, 10., 1998, Utrecht. Procedings..., 1998.

BARROS, L; DENIS, N; NÚÑES, A. Prueba del alcohol en leche y relación con calcio iónico. Práticas Veterinárias, v. 9, p. 315, 1999.

BARROS, L.; DENIS, N.; NÚNES, A.; GONZÁLEZ, O.; GALIN, C.; TORRES, E.; GONZÁLEZ, P. Variations of milk and alcohol test. WORLD BUIATRICS CONGRESS, 21., Punta del Este. Anales..., 2000. p. 577.

BRASIL. Ministério da Agricultura, Pecuária e Abastecimento. Instrução Normativa no 22, de 14/04/2003. Diário Oficial da União, Brasília, DF, seção I, p. 3, 2 maio 2003.

BRASIL. Ministério da Agricultura, Pecuária e Abastecimento. Instrução Normativa n 51, de 18/09/2002. Diário Oficial da União, Brasília, n. 183, seção I, p. 13-22, 20 set. 2002.

DAVIES, D.T.; WHITE, J.C.D. The relation between the chemical composition of milk and the stability of the caseinate complex: IIcoagulation by ethanol. J. Dairy Res., v. 25, p. 256-267, 1958.

DONATELE, D.M.; VIEIRA, L.F.P.; FOLLY, M.M. Relação do teste de alizarol a $72 \%$ (v/v) em leite "in natura" de vaca com acidez e contagem de células somáticas: análise microbiológica. Hig. Alim., v. 17, n. 110, p. 95-100, 2003.

GONZÁLEZ, F.H.D.; SCHEFFER, J.F.S. Perfil sangüíneo: ferramenta de análise clínica, metabólica e nutricional. In: GONZÁLEZ, F.H.D. (Ed.). Avaliação metabólico-nutricional de vacas leiteiras por meio de fluidos corporais. Porto Alegre: UFGRS, 2002. p. 5-17.

HORNE, D.S.; PARKER, T.G. Factors affecting the ethanol stability of bovine milk: I- Effect of serum phase components. J. Dairy Res., v. 48, p. 273-284, 1981.

INTERNATIONAL DAIRY FEDERATION. Milk: Enumeration of somatic cell. (IDF Standard 148 A). Brussels: IDF/FIL, 1995.
LANGONI, H. Tendências de modernização de setor lácteo: monitoramento da qualidade do leite pela contagem de células somáticas. Revista educação continuada do CRMV SP, v. 3, n. 3, p. 57-64, 2000.

LUCCI, C.S. Nutrição e manejo de bovinos leiteiros. São Paulo: Manole, 1997.

MITAMURA, K. Studies on the alcohol coagulation of fresh cow milk. J. Fac. Agric. Hokkaido Univ., v. 41, p. 102-364, 1937.

MOUSSAOUI, F.; MICHELUTTI, I.; LE ROUX, Y.; LAURENT, F. Mechanisms involved in milk endogenous proteolysis induced by a lipopolysaccharide experimental mastitis. J. Dairy Sci., v. 85, n. 10, p. 2562-2570, 2002.

PECORARI, M.; FOSSA, E.; AVANZINI, G.; MARIAN, P. Milk with abnormal coagulation: Acidity, chemical composition and observation on the metabolic profile of the cow. Sci. Tec. Latt-Cas., v. 4, p. 263-278, 1984. PEREIRA, D.B.C., SILVA, P.H.F., COSTA Jr, L.C.G., OLIVEIRA, L.L. Físicoquímica do Leite e Derivados - Métodos Analíticos. $2^{a}$ ed. Juíz de Fora: EPAMIG, 2001, 234 p.

PHILPOT, W.N. Programas de qualidade do leite no mundo. SIMPÓSIO INTERNACIONALSOBREQUALIDADEDOLEITE, 1998, Curitiba. Anais..., 1998. p. 16.

PONCE, P. Caracterização da síndrome do leite anormal: um enfoque das suas possíveis causas e correção. SIMPÓSIO INTERNACIONAL SOBRE PRODUÇÃO INTENSIVA DE LEITE, 4., 1999, Caxambu. Anais..., 1999, p. 61-76.

PONCE, P.; HERNÁNDEZ. R. (2001). Propriedades físico-químicas do leite e sua associação com transtornos metabólicos e alterações na glândula mamária. In: GONZÁLEZ, F.H.D.; DÜRR, J.W.; FONTANELI, R.S. (Ed.). Uso do leite para monitorar a nutrição e o metabolismo de vacas leiteiras. Porto Alegre: UFGRS, 2001. p. 58-68.

TIMM, C.D.; OLIVEIRA, D.S.; ARRIADA, E.O.; MORAES, C.M.; ROOS, T.B.; GONZALEZ, H.L. Estabilidade protéica do leite produzido no município de Santa Vitória do Palmar. CONGRESSO BRASILEIRO DE MEDICINA VETERINÁRIA, 29., 2002, Gramado. Anais..., 2002. CD-ROM.

VARNAM, A.H.; SUTHERLAND, J.P. Leche y productos lácteos: tecnología, química y microbiología. Zaragoza: Acribia, 1995.

WALSTRA, P.; JENNESS, R. Química y física lactológica. Zaragoza: Acribia, 1987. 